inhibition of such reactions by hexachloroiridate(IV) has been attributed to rapid oxidation of platinum(III), but the evidence favoring the interpretations in question, while reasonable, has been for the most part indirect and qualitative. We now wish to report quantitative evidence for the intermediate formation of platinum(III) in the chemical oxidation of certain platinum(II) complexes and to describe some features of the chemistry of the intermediate platinum(III) species as revealed by observation of their competitive reactions including oxidation by hexachloroiridate(IV).

Our principal observations relate to the oxidation of tetrachloroplatinate(II) by hexachloroiridate(IV), according to eq 1 , in aqueous sodium chloride-hydrochloric

$$
\mathrm{PtCl}_{4}{ }^{2-}+2 \mathrm{IrCl}_{6}{ }^{2-}+2 \mathrm{Cl}^{-} \longrightarrow \mathrm{PtCl}_{6}{ }^{2-}+2 \mathrm{IrCl}_{6}{ }^{3-}
$$

acid solution. The stoichiometry of the reaction was established spectrophotometrically and the kinetics were determined, also spectrophotometrically, over the following initial concentration ranges of reactants and products: $4.0 \times 10^{-5}$ to $2.5 \times 10^{-3} \mathrm{M} \mathrm{PtCl}_{4}{ }^{2-}$, $1.3 \times 10^{-4}$ to $8.0 \times 10^{-4} \mathrm{M} \mathrm{IrCl}_{6}{ }^{2-}, 0$ to $8.0 \times 10^{-2}$

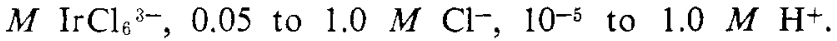
Throughout this combination of concentration ranges the kinetics of the reaction were accurately represented by the rate law, expressed by eq 2 , which is derived,

$$
\begin{aligned}
\frac{-\mathrm{d}\left[\mathrm{IrCl}_{6}{ }^{2-}\right]}{\mathrm{d} t}=\frac{-2 \mathrm{~d}\left[\mathrm{PtCl}_{4}{ }^{2-}\right]}{\mathrm{d} t}= \\
\frac{2 k_{1} k_{2}\left[\mathrm{PtCl}_{4}{ }^{2-}\right]\left[\mathrm{IrCl}_{6}{ }^{2-}\right]^{2}\left[\mathrm{Cl}^{-}\right]}{k_{-1}\left[\mathrm{IrCl}_{6}{ }^{3-}\right]+k_{2}\left[\mathrm{IrCl}_{6}{ }^{2-}\right]\left[\mathrm{Cl}^{-}\right]}
\end{aligned}
$$

employing the steady-state approximation for $\mathrm{PtCl}_{4}^{-}$, on the basis of the mechanism depicted by eq 3-5.

$$
\begin{aligned}
\mathrm{PtCl}_{4}^{2-}+\mathrm{IrCl}_{6}{ }^{2-} \underset{k_{-1}}{\stackrel{k_{1}}{\longrightarrow}} \mathrm{PtCl}_{4}^{-}+\mathrm{IrCl}_{6}{ }^{3-} \\
\mathrm{PtCl}_{4}^{-}+\mathrm{IrCl}_{6}^{2-}+\mathrm{Cl}^{-} \stackrel{k_{2}}{\longrightarrow} \mathrm{PtCl}_{5}^{-}+\mathrm{IrCl}_{6}^{3-} \\
\mathrm{PtCl}_{5}^{-}+\mathrm{Cl}^{-} \longrightarrow \mathrm{PtCl}_{6}{ }^{2-}
\end{aligned}
$$

Our kinetic measurements at $25^{\circ}$, and an ionic strength of $1.0 \mathrm{M}$, maintained with $\mathrm{NaClO}_{4}$, yield the values $k_{1}=0.62 \pm 0.03 \mathrm{M}^{-1} \mathrm{sec}^{-1}$ and $k_{-1} / k_{2}=9.0 \times 10^{-3}$ $M$. The rate was unaffected by variation of the concentration of $\mathrm{H}^{+}$between $10^{-5}$ and $1 \mathrm{M}$ and by the addition of up to $10^{-3} \mathrm{M} \mathrm{PtCl}_{6}{ }^{2-}$.

An obvious variant of this mechanism, which is kinetically indistinguishable from that depicted above, is one in which the termolecular step 4 is replaced by a sequence of bimolecular steps (eq 6 and 7). This

$$
\begin{gathered}
\mathrm{PtCl}_{4}^{-}+\mathrm{Cl}^{-} \stackrel{K}{\stackrel{\leftrightarrow}{\rightleftarrows}} \mathrm{PtCl}_{5}^{2-} \text { (rapid equilibrium) } \\
\mathrm{PtCl}_{5}^{2-}+\mathrm{IrCl}_{6}{ }^{2-} \stackrel{k_{2}^{\prime}}{\longrightarrow} \mathrm{PtCl}_{5}^{-}+\mathrm{IrCl}_{6}^{3-}
\end{gathered}
$$

variant leads to a rate law identical in form with eq 2 , in which $k_{2}$ is replaced by $k_{2}{ }^{\prime} K$. The observed value of $9.0 \times 10^{-3} M$ then refers to $k_{-1} / k_{2}{ }^{\prime} K$, instead of to $k_{-1} / k_{2}$. Favoring this formulation is the recent direct observation ${ }^{4}$ of the formation of $\mathrm{PtCl}_{5}{ }^{2-}$ in aqueous solution by dissociation of $\mathrm{PtCl}_{6}{ }^{3-}$ following electron capture by $\mathrm{PtCl}_{6}{ }^{2-} .4$

(1) R. L. Rich and H. Taube, J. Am. Chem. Soc., 76, 2608 (1954).

(2) A. W. Adamson and A. H. Sporer, ibid., 80, 3865 (1958).

(3) A. J. Pöe and M. S. Vaidya, J. Chem. Soc., 2981 (1961)

(4) G. E. Adams, R. B. Broszkiewicz, and B. D. Michael, Trans. Faraday Soc., 64, 1256 (1968)
Using the stopped-flow method, we have also investigated the kinetics of the oxidation of $\mathrm{Pt}(\mathrm{en})_{2}{ }^{2+}(\mathrm{en}=$ ethylenediamine) by $\mathrm{IrCl}_{6}{ }^{2-}$ (eq 8 ) and, in this case also,

$\mathrm{Pt}(\mathrm{en})_{2}{ }^{2+}+2 \mathrm{IrCl}_{6}{ }^{2-}+2 \mathrm{Cl}^{-} \longrightarrow$

$$
\text { trans } \cdot \mathrm{Pt}(\mathrm{en})_{2} \mathrm{Cl}_{2}{ }^{2+}+2 \mathrm{IrCl}_{6}{ }^{3-}
$$

found evidence for a stepwise mechanism involving an intermediate platinum(III) species, $\mathrm{Pt}(\mathrm{en})_{2}{ }^{3+}$ (or, alternatively, $\mathrm{Pt}(\mathrm{en})_{2} \mathrm{Cl}^{2+}$ or $\mathrm{Pt}(\mathrm{en})_{2} \mathrm{Cl}_{2}{ }^{+}$). Over the initial concentration ranges, $6.2 \times 10^{-5}$ to $2.5 \times 10^{-4} \mathrm{M}$ $\mathrm{Pt}(\mathrm{en})_{2}{ }^{2+}, 1.3 \times 10^{-5}$ to $2.5 \times 10^{-5} M \mathrm{IrCl}_{6}{ }^{2-}, 0$ to $1.0 \times 10^{-3} M \mathrm{IrCl}_{6}{ }^{3-}, 10^{-5}$ to $0.5 \mathrm{M} \mathrm{H}^{+}$, and 0.1 to $1.0 \mathrm{M} \mathrm{Cl}^{-}$, the kinetics of this reaction accurately obeyed the rate law described by eq 9 , which is derived,

$$
\begin{aligned}
\frac{-\mathrm{d}\left[\mathrm{IrCl}_{6}{ }^{2-}\right]}{\mathrm{d} t}=\frac{-2 \mathrm{~d}\left[\mathrm{Pt}(\mathrm{en})_{2}{ }^{2+}\right]}{\mathrm{d} t}= \\
\frac{2 k_{1}{ }^{\prime}{k_{2}}^{\prime \prime}\left[\mathrm{Pt}(\mathrm{en})_{2}{ }^{2+}\right]\left[\mathrm{IrCl}_{6}{ }^{2-}\right]^{2}\left[\mathrm{Cl}^{-}\right]^{2}}{k_{-1}{ }^{\prime}\left[\mathrm{IrCl}_{6}{ }^{3-}\right]+{k_{2}}^{\prime \prime}\left[\mathrm{IrCl}_{6}{ }^{2-}\right]\left[\mathrm{Cl}^{-}\right]^{2}}
\end{aligned}
$$

employing the steady-state approximation for $\mathrm{Pt}(\mathrm{en})_{2}{ }^{3+}$, for the mechanism depicted by eq 10 and 11 . Our kinetic

$$
\begin{gathered}
\mathrm{Pt}(\mathrm{en})_{2}{ }^{2+}+\mathrm{IrCl}_{6}{ }^{2-} \underset{k_{-1^{\prime}}}{\stackrel{k 1^{\prime}}{\rightleftharpoons}} \mathrm{Pt}(\mathrm{en})_{2}{ }^{3+}+\mathrm{IrCl}_{6}{ }^{3-} \\
\mathrm{Pt}(\mathrm{en})_{2}{ }^{3+}+\mathrm{IrCl}_{6}{ }^{2-}+2 \mathrm{Cl}^{-} \stackrel{k 2^{\prime \prime}}{\longrightarrow} \mathrm{Pt}(\mathrm{en})_{2} \mathrm{Cl}_{2}{ }^{2+}+\mathrm{IrCl}_{6}{ }^{3-}
\end{gathered}
$$

measurements (also at $25^{\circ}$ and $1.0 \mathrm{M}$ ionic strength, maintained with $\mathrm{NaClO}_{4}$ ) yield the values $k_{1}{ }^{\prime}=$ $(1.40 \pm 0.05) \times 10^{5} \mathrm{M}^{-1} \mathrm{sec}^{-1}$ and $k_{-1}{ }^{\prime} / k_{2}{ }^{\prime \prime}=2.0 \times$ $10^{-2} M^{2}$. The $\sim 10^{5}$-fold difference between the value of $k_{1}$ for $\mathrm{PtCl}_{4}{ }^{2-}$ and $k_{1}{ }^{\prime}$ for $\mathrm{Pt}(\mathrm{en})_{2}{ }^{2+}$ is in the direction expected from the difference between the charges of the two reactants.

Preliminary kinetic observations also point to similar mechanisms for the oxidations of $\mathrm{PtCl}_{3}\left(\mathrm{C}_{2} \mathrm{H}_{4}\right)^{-}$and $\mathrm{PtCl}_{2}\left(\mathrm{OH}_{2}\right)\left(\mathrm{C}_{2} \mathrm{H}_{4}\right)$ by $\mathrm{IrCl}_{6}{ }^{2-}$. The reactivities of these complexes are lower than those of $\mathrm{PtCl}_{4}{ }^{2-}$ and $\mathrm{Pt}(\mathrm{en})_{2}{ }^{2+}$, presumably reflecting stabilization of the +2 oxidation state of platinum by the coordinated ethylene. The oxidation of these complexes is accompanied by release of the ethylene which does not itself undergo oxidation. ${ }^{5}$

Acknowledgment. Support of this work through grants from the National Science Foundation and the Advanced Research Projects Agency is gratefully acknowledged. One of us (M. P.) also thanks the U. S. Government Fulbright-Hays Program for a travel grant and the University of Zagreb for a leave of absence.

(5) P. B. Chock and J. Halpern, unpublished results.

Jack Halpern, Marijan Pribanic Department of Chemistry, University of Chicago Chicago, Illnois 60637 Received August 14, 1968

\section{Photosensitized Decomposition of Some Cobalt Ammines}

Sir:

We wish to report the finding that the redox decomposition of $\mathrm{Co}\left(\mathrm{NH}_{3}\right)_{6}{ }^{3+}$ and $\mathrm{Co}\left(\mathrm{NH}_{3}\right)_{5}\left(\mathrm{H}_{2} \mathrm{O}\right)^{3+}$ in various aqueous and organic solvents is photosensitized by organic compounds known to have relatively stable triplet excited states. This effect, while forshadowed 
Table I. Systems Showing Sensitized Redox Decomposition of Co(III) Ammines ${ }^{a}$

\begin{tabular}{llll}
\hline \multicolumn{1}{c}{ Sensitizer } & \multicolumn{1}{c}{ Solvent } & \multicolumn{1}{c}{ Complex } & Wavelength, m $\mu$ \\
\hline Benzil & $80 \%$ ethanol-water & {$\left[\mathrm{Co}\left(\mathrm{NH}_{3}\right)_{5}\left(\mathrm{H}_{2} \mathrm{O}\right)\right]\left[\mathrm{ClO}_{4}\right]_{3}$} & $350-370$ \\
trans-Stilbene-4-carboxylic acid & $80 \%$ ethanol-water & {$\left[\mathrm{Co}\left(\mathrm{NH}_{3}\right)_{5}\left(\mathrm{H}_{2} \mathrm{O}\right)\right][\mathrm{ClO}]_{3}$} & $350-370$ \\
& $3 \mathrm{M}$ aqueous $\mathrm{NaOH}$ & $\mathrm{Co}\left(\mathrm{NH}_{3}\right)_{6} \mathrm{Cl}_{3}$ & $350-370$ \\
Benzophenone & $50 \%$ ethanol-water & $\mathrm{Co}\left(\mathrm{NH}_{3}\right)_{6} \mathrm{Cl}_{3}$ & $350-370$ \\
Biacetyl & Dimethylacetamide & {$\left[\mathrm{Co}\left(\mathrm{NH}_{3}\right)_{5}\left(\mathrm{H}_{2} \mathrm{O}\right)\right]\left[\mathrm{ClO}_{4}\right]_{3}$} & $405-415$ \\
& $50 \%$ ethanol-water & $\mathrm{Co}\left(\mathrm{NH}_{3}\right)_{6} \mathrm{Cl}_{3}$ & $405-415$ \\
\hline
\end{tabular}

${ }^{a}$ Ca. $0.01 M$ sensitizer and complex. ${ }^{b}$ In very low efficiency.

by previous observations that coordination compounds can quench organic triplet state species, ${ }^{1-3}$ does not seem to have been reported before.

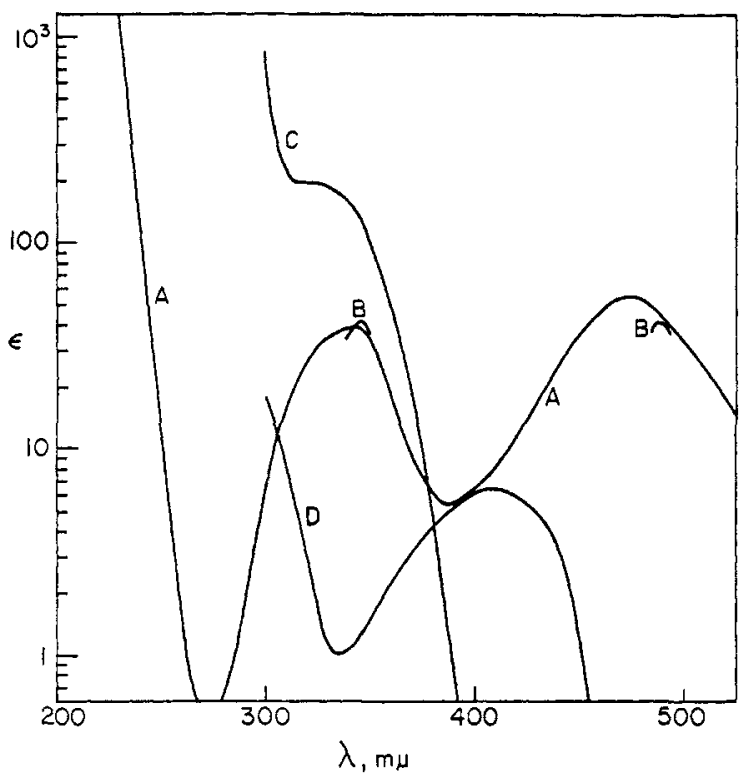

Figure 1. Absorption spectra: (A) $\mathrm{Co}\left(\mathrm{NH}_{3}\right)_{6} \mathrm{Cl}_{3}$, (B) corresponding maxima for $\left[\mathrm{Co}\left(\mathrm{NH}_{3}\right)_{5}\left(\mathrm{H}_{2} \mathrm{O}\right)\right]\left[\mathrm{ClO}_{4}\right]_{3}$, (C) benzophenone, (D) biacetyl. The latter two spectra are for $50 \%$ ethanol-water solutions.

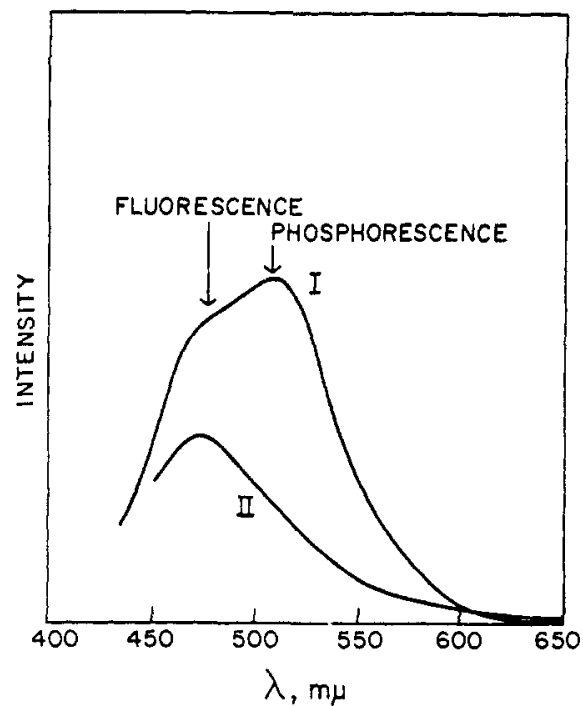

Figure 2. Emission spectra for $0.15 \mathrm{M}$ biacetyl in $50 \%$ ethanolwater solution: (I) biacetyl alone; (II) with added $0.005 M$ Co$\left(\mathrm{NH}_{3}\right)_{6} \mathrm{Cl}_{3}$.

(1) A. J. Fry, R. S. H. Liux, and G. S. Hammond, J. Am. Chem. Soc., 88, 4781 (1966).

(2) L. Lindquist, Acta Chem. Scand., 20, 2067 (1966).

(3) See H. Linschitz and L. Pekkarinen, J. Am. Chem. Soc., 82, 2411 (1960).
The above two complex ions are photosensitive in their own right. With $254-\mathrm{m} \mu$ light, both undergo photoredox decomposition to $\mathrm{Co}$ (II) and oxidized ammonia, ${ }^{4}$ the first with a quantum yield of about 0.9 and the second with one of about 0.07 . The absorption band irradiated is the first charge-transfer (CT) one in both cases, as indicated in Figure 1. Irradiation of either the first or the second ligand field band gives only a trace of decomposition, the reported quantum yields being about $10^{-35}$ and $5 \times 10^{-4},{ }^{6}$ respectively. The photosensitivity of these two complexes is thus confined to the CT band.

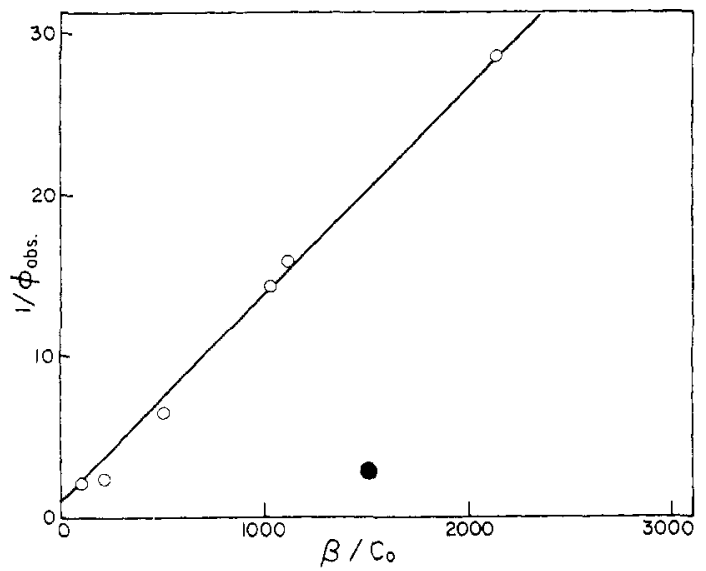

Figure 3. Data for the benzophenone-sensitized decomposition of $\mathrm{Co}\left(\mathrm{NH}_{3}\right)_{6}{ }^{3+}$ plotted according to eq 4: $O$, nondeaerated solutions; $\bullet$, deaerated solution.

Our general observations are summarized in Table I. In each case, irradiation produced $C$ (II) with a qualitatively high efficiency in the presence of the sensitizer, and not at all in its absence. The Co(II) determinations were made by means of a colorimetric method involving complexation with thiocyanate $;^{7}$ Reineckate actinometry ${ }^{8}$ was used.

Some quantitative measurements were made with biacetyl and with benzophenone as sensitizers. With $0.15 M$ biacetyl and $0.005 M \mathrm{Co}\left(\mathrm{NH}_{3}\right)_{6}{ }^{3+}$ in $50 \%$ ethanol-water solution, the quantum yield for $\mathrm{Co}$ (II) production was 0.056 at room temperature, based on the total absorbed intensity of $410-\mathrm{m} \mu$ irradiating light. This wavelength corresponds to the first singlet--singlet transition of biacetyl, as shown in Figure 1. Biacetyl is unusual in showing both fluorescent and phosphorescent emission at room temperature, and the combined emis-

(4) J. F. Endicott and M. Z. Hoffman, ibid., 87, 3348 (1965).

(5) A. W. Adamson, Discussions Faraday Soc., 29, 163 (1960).

(6) D. Klein and C. W. Moeller, Inorg. Chem., 4, 394 (1965).

(7) R. E. Kitson, Anal. Chem., 22, 664 (1950).

(8) E. Wegner and A. W. Adamson, J. Am. Chem. Soc., 88, 394 (1966). 
sion spectrum is shown in Figure 2 (as determined with 400-m $\mu$ stimulating light, using an Aminco emission spectrometer). In the presence of the complex, however, the phosphorescent or triplet-state emission is quenched, but not that of the first singlet state. The implication is that it is the triplet state that is active in the sensitization.

In addition, a series of measurements was carried out using benzophenone as sensitizer and various concentrations of complex. An oxygen effect is present at least in this particular system, since the yield for Co(II) production rose from 0.064 to 0.36 on thorough degassing of the solution. Further, the quantum yield of the nondeaerated solutions decreases with decreasing complex concentration, presumably as a result of competition between deactivation of the sensitizer by the complex and by other processes. The following reaction scheme is thus suggested

$$
\begin{gathered}
\mathrm{S} \stackrel{h_{\nu}}{\longrightarrow} \mathrm{S}^{*} \longrightarrow \mathrm{T} \\
\mathrm{T} \stackrel{k_{1}}{\longrightarrow} \mathrm{S} \\
\mathrm{T}+\mathrm{C} \stackrel{k_{2}}{\longrightarrow} \mathrm{S}+\mathrm{Co}(\mathrm{II})
\end{gathered}
$$

where $S$ denotes sensitizer and $\mathrm{T}$ its triplet state, produced via an excited singlet state $\mathrm{S}^{*}$, $\mathrm{T}$ being produced in over-all quantum yield $\phi$. It is assumed that the complex, $C$, may reactively deactivate $T$. In the present case $\mathrm{C}$ diminishes with time; assuming $\mathrm{d}[\mathrm{T}] / \mathrm{d} t=0$, i.e., stationary-state kinetics, one obtains

$$
1 / \phi_{\text {obsd }}=1 / \phi+\left(k_{1} / k_{2} \phi\right)\left(\beta / C_{0}\right)
$$

where $\phi_{\text {obsd }}$ is the observed quantum yield for $\mathrm{Co}$ (II) formation, $C_{0}$ is the initial complex concentration, and $\beta$ is given by

$$
\beta=\left[C_{0} /\left(C_{0}-C\right)\right] \ln \left(C_{0} / C\right)
$$

with $C$ now denoting the final complex concentration.

The results are plotted according to eq 4 in Figure 3, and the intercept and slope give about unity and 0.013 for $\phi$ and $k_{1} / k_{2}$, respectively. If reaction 3 is diffusion controlled, $k_{2}$ should be about $6 \times 10^{9} \mathrm{M}^{-1} \mathrm{sec}^{-1,9}$ which would then make $k_{1}$ about $8 \times 10^{7} \mathrm{sec}^{-1}$. This last value is similar to those reported for other systems involving benzophenone. ${ }^{10}$

Our investigations are continuing, but some preliminary discussion is appropriate here. The wavelengths of the stimulating light used, as well as those corresponding to the triplet-state energies of the various sensitizers, are much longer than the threshold wavelengths for direct photodecomposition of these complexes. This situation plus the lack of any appreciable photosensitivity of the $d-d$ bands themselves make it seem unlikely that energy transfer has occurred into the $\mathrm{d}-\mathrm{d}$ or ligand field system. On the other hand, the first CT bands of these complexes lie at much higher energies than available here. The remaining possibility seems to be that the sensitizers are interacting with CT triplet states of the complexes. Such triplet states must exist in principle, and their theoretical description has been discussed to some extent. ${ }^{11}$ The actual

(9) J. G. Calvert and J. N. Pitts, Jr., "Photochemistry," John Wiley and Sons, Inc., New York, N. Y., 1966.

(10) H. L. Bäckström and K. Sandros, Acta Chem. Scand, 14, 48 (1960)

(11) C. K. Jorgensen, "Absorption Spectra and Bonding in Complexes," Pergamon Press, London, 1962. singlet-triplet $C T$ transitions are not evident in the absorption spectra of $\mathrm{Co}$ (III) complexes, presumably because of being hidden by more intense $d-d$ ones. Our suggestion is then that the sensitized decompositions reported here are those of low-lying CT triplet states which happen not to be easily populated by direct absorption of light.

Acknowledgment. These investigations were supported in part by Contract DA-31-124-ARO-D-343 with the U. S. Army Research Office, Durham.

$$
\begin{array}{r}
\text { Arnd Vogler, Arthur W. Adamson } \\
\text { Department of Chemistry, University of Southern California } \\
\text { Los Angeles, California } 90007 \\
\text { Received July 23, } 1968
\end{array}
$$

Studies of Free Radicals. II. Chemical Properties of Nitronylnitroxides. A Unique Radical Anion

Sir:

In an earlier communication the preparation of the highly stable aromatic nitronylnitroxide radicals III $(\mathrm{R}=\mathrm{Ar})$ was described. ${ }^{1}$ We now report on some unusual chemical properties of the nitronylnitroxide grouping.

The alkylnitronylnitroxides III $(\mathrm{R}=$ alkyl) are prepared like their aromatic analogs by treatment of the bishydroxylamine I with aldehydes to give tetrahydroimidazoles II, which are subsequently oxidized with aqueous sodium periodate or lead dioxide. The resulting radicals are deep red solids which display esr spectra in solution having basic five-line patterns caused by coupling with two equivalent nitrogen nuclei. Further splitting of each line by the $\alpha$-alkyl hydrogens usually is also observed together with occasionally resolved very weak coupling with the twelve methyl hydrogens (Table I).

Table I. Coupling Constants (in gauss) ${ }^{a}$ of Nitronylnitroxides III in Benzene

\begin{tabular}{llrc}
\multicolumn{1}{c}{$\mathrm{R}$} & \multicolumn{1}{c}{$a_{\mathrm{N}}$} & $a_{\alpha-\mathrm{H}}$ & $a_{4,5-\mathrm{CH}_{3}}$ \\
\hline $\mathrm{CH}_{3}$ & 7.42 & 3.3 & 0.21 \\
$\mathrm{CH}_{2} \mathrm{CH}_{3}$ & 7.42 & 2.0 & \\
$\left(\mathrm{CH}_{2}\right)_{12} \mathrm{CH}_{3}$ & 7.45 & 2.1 & \\
$\mathrm{CH}_{2} \mathrm{OH}$ & 7.48 & 2.2 & 0.2 \\
$\mathrm{CH}\left(\mathrm{CH}_{3}\right)_{2}$ & 7.5 & $\sim 0.9$ & \\
$\mathrm{CH}\left(\mathrm{OC}_{2} \mathrm{H}_{5}\right)_{2}$ & 7.25 & $<0.5$ & 0.24 \\
\hline
\end{tabular}

${ }^{a} \pm 0.03$ gauss.

Although many of these radicals can be stored at room temperature for several weeks without decomposition, the radicals bearing $\alpha$ hydrogens are somewhat less stable than their aromatic analogs. By comparison, however, the hydroxymethylnitronylnitroxide III (R $\left.=\mathrm{CH}_{2} \mathrm{OH}\right)^{2}$ was exceptionally labile and was found to undergo a gradual change on standing that could be greatly accelerated in alcoholic sodium hydroxide. The almost exclusive product of this reaction was a new red water-soluble radical, identified as III, $\mathrm{R}=$ $\mathrm{H},{ }^{2}$ from its esr pattern of five doublets $\left[a_{\mathrm{N}}=7.26\right.$,

(1) J. H. Osiecki and E. F. Ullman, J. Am. Chem. Soc., 90, 1078 (1968).

(2) Mass spectral and analytical data were in accord with the assigned structure. 